\title{
Libro: Mi aparente fragilidad. La identidad política en el discurso de Cristina Fernández de Kirchner, 2007-2011
}

Irene Lis Gindin

Prometeo, Buenos Aires, 2019 (180 pp.)

\section{Julia de Diego}

Investigadora en el Instituto de Estudios Histórico-Sociales de la Universidad Nacional del Centro de la Provincia de Buenos Aires, Argentina.

E-mail: juliadediego@yahoo.com.ar

El discurso político y su capacidad de persuasión han sido un objeto privilegiado desde la Grecia clásica hasta nuestros días. Con los debates en el ágora pública nacen las primeras reflexiones en torno a las capacidades oratorias, los modos de organizar y adecuar el discurso y el rol de los auditorios en las posibilidades de ejercer la política pública.

El libro Mi aparente fragilidad se inscribe en esta misma inquietud: ¿cómo es que el discurso político público persuade? A lo cual suma una pregunta indispensable: ¿cómo esta dimensión argumentativa al mismo tiempo tensiona, debate y se diferencia de otros discursos y, en ese mismo proceso, construye una identidad política?

Con este objetivo, recupera la clásica categoría aristotélica de ethos, es decir, el modo en que el discurso argumenta a partir de la imagen que proyecta el enunciador sobre sí mismo, pero revisitada desde las últimas conceptualizaciones. Ahora el ethos no es solo un modo organizativo y argumentativo del discurso, sino también una forma en la que se inscribe la polémica en él. Esta línea había sido inaugurada por autores contemporáneos como Ruth Amossy (2016), quien plantea una relectura de la retórica que la acerca al conflicto adversativo y la aleja de los modos correctos del hablar público. La retórica actual es la retórica del dissensus, afirma Amossy.

Pero la obra de Irene Gindin no solo parte de una preocupación teórica, sino también de una pregunta político-histórica y esta es ¿qué características sociodiscursivas asumió el kirchnerismo como movimiento político y en qué medida, el impacto de los acontecimientos políticos fue configurando una identidad política $\mathrm{y}$ un liderazgo particular? En otras palabras, Mi aparente fragilidad se estructura interrogándose ¿cómo y cuándo el kirchnerismo empezó a ser kirchnerismo y no solo la presidencia de Néstor Kirchner o de Cristina Fernández?

Para hacerlo observa, por un lado, el modo en que la ex mandataria aparece en su propio discurso - a través de la categoría de ethos político- y cómo su figura enunciativa argumenta y se vuelve garante de sus propios dichos a partir de construir una imagen de sí misma y de ciertos colectivos con los que se identifica. 
Desde la tapa, en la que Cristina Fernández aparece sola, elevada por encima de -y al mismo tiempo sostenida por- sus seguidores, el libro nos propone un recorrido en el que la fragilidad de lo humano y la fortaleza de lo político se conjugan en lo afectivo de la representación.

El portavoz, como decía Bourdieu (1984), está ahí y habla con la palabra legítima solo porque puede decir en nombre de un grupo y, al mismo tiempo, ese colectivo es tal cual es, porque el líder lo delinea en sus palabras. La identidad política kirchnerista cementa este vínculo con afecto. Las siluetas de la tapa del libro la sostienen, la legitiman, la quieren.

La líder es alguien que está por encima, pero al mismo tiempo empatiza emotivamente con sus seguidores. Conceptualmente para Irene Gindin esto se vuelve visible a través de dos tipos de ethos, el magistral que aparece cuando se busca explicar algo que se sabe a quienes no lo conocen; y el íntimo, a través del cual expresa y comparte el dolor propio y ajeno. El primero se encuentra más bien ligado a la dimensión política (donde los argumentos son personales y se vinculan a su trayectoria, las causas que ha defendido y la posesión del saber). El ethos intimo evidencia la humanidad de la líder, su dolor y su condición de mujer. De allí la elocuente frase emitida en cadena nacional en noviembre de 2010, luego de la muerte de Néstor Kirchner: "no es mi momento más difícil, sino el más doloroso".

Esa frase parecería indicar que lo difícil queda para la política, mientras que lo doloroso es lo personal, la pérdida. Esta escisión refuerza una de las ideas centrales del libro que es: el dolor personal no afecta la fortaleza política. Consideramos que en esta tensión transita gran parte de la lectura que realiza la autora.

La perspectiva de género que también analiza el libro Mi aparente fragilidad, se nos aparece casi como una metáfora de esta tensión entre el afecto-dolor-intimidad y la política-fuerza-saber. Lo femenino sería en la perspectiva de género que fabrica Cristina, justamente, un lugar de enunciación cómodo para anudar la fuerza con la intimidad; para consolidar esta fusión propia de la identidad kirchnerista, pero también peronista.

Ya lo preanunciaba -de distinta manera- Eva Perón, cuando en su discurso del $1^{\circ}$ de mayo de 1952, luego de mostrar su fuerza diciendo que saldrá con las mujeres del pueblo para "no dejar en pie ningún ladrillo que no sea peronista", expresa lo afectivo/femenino: "Estoy con ustedes para hacer un arco iris de amor entre el pueblo y Perón; estoy con ustedes para hacer ese puente de amor y de felicidad que tracé entre ustedes y el líder de los trabajadores".

La construcción de los enemigos y los colectivos de identificación, es decir el modo en que los nombró e interpeló, fue lo que, según explica Irene Gindin, terminó de dar sentido a la construcción identitaria en el discurso presidencial. Los enemigos adjudicados al "neoliberalismo" (que se asocian a la dictadura, al campo y a los medios de comunicación) y, como contraparte, sus sostenes -los peronistas, las mujeres, la generación del bicentenario-, son todas figuras discursivas que se vuelven clave en la delimitación identitaria. Hasta aquí llega quien soy y a partir de acá se ubican quienes nunca podrán comprendernos, porque no hablan desde la democracia. 
Este último aspecto resulta sumamente relevante, entendiendo que desde la transición democrática hasta hoy, las tensiones en torno a lo que es y no es democracia son claves en la construcción de posicionamientos y los órdenes políticos. Como dice Laclau, analizar los debates en torno a la democracia sirve para "explicar la semántica política de nuestro mundo político contemporáneo" (2004: 5).

El modo en que el libro está escrito y organizado evidencia un alentador desafío que ha enfrentado la autora: un abordaje desde la cercanía a los acontecimientos políticos, emotiva y temporalmente, que no ladea un modo responsable, sistemático, crítico y reflexivo de hacer ciencia. Este texto muestra un logro que es el de una escritura sin anteojeras partidarias, pero con convicciones políticas necesarias. En Mi aparente fragilidad encontramos herramientas para comprender un modo de pensarnos, convencidos de que es mejor hablar y debatir y estudiar la actualidad, antes que llegar tarde a decidir cómo queremos ser. Observamos allí un abordaje denso y complejo de las configuraciones discursivas y simbólicas de la política, sin determinismos y acorde a los desafíos actuales de un contexto mediatizado. En este mismo sentido, asiste a la necesidad de respetar la complejidad de los procesos que se estudian y establecer el compromiso con una construcción de conocimiento acorde a esa complejidad.

\section{Bibliografía}

Amossy, R. (2016). Por una retórica del dissensus: las funciones de la polémica. En A. S. Montero (Comp.), El análisis del discurso polémico (pp. 25-38). Buenos Aires, Argentina: Prometeo.

Bourdieu, P. (1988). La delegación y el fetichismo político. En Cosas Dichas (pp. 158-172), Barcelona, España: Gedisa.

Laclau, E. (2004). Discurso. Topos y tropos, (1), 1-7.

Recibido: 28/04/2019. Aceptado: 31/05/2019. 